\title{
Por que falar de imigração no Brasil?
}

\author{
Entrevista com a Prof". Márcia Oliveira* \\ Por Kassoum DIÉMÉ**
}

A Profa. Márcia Maria de Oliveira que está envolvida nas questões migratórias há pelo menos duas décadas fala a respeito da imigração haitiana no Brasil, em particular na cidade de Manaus. Partindo de um olhar mais geral acerca da migração no mundo e dos desafios dos pesquisadores e dos estudos sobre este tema, ela se pronuncia sobre um elemento usualmente pouco explorado na atual imigração Brasileira: a situação da mulher haitiana enquanto migrante no norte brasileiro. Portanto, ela aponta a complexidade do fenômeno migratório haitiano, sugerindo também que a presença haitiana no Brasil não é uma casualidade nem resultou no que se poderia conceber como "uma benção" na ótica de boa parte dos imigrantes. Porém, a frustração parece atingir muito mais as mulheres para as quais um mercado de trabalho, pouco sonhado por elas, Ihes abriu possibilidades mais do que qualquer outro no Brasil.

Professora, há quanto tempo e como você se tornou estudiosa das migrações?

M. O.: Já são mais de trinta anos, acredito. Eu comecei a estudar o tema das migrações quando ingressei na vida religiosa das irmãs missionárias de São Carlos Borromeu - Scalabrinianas, que lidam diretamente com a questão do atendimento aos migrantes. E junto com o atendimento eu fui me despertando para estudar a temática das migrações. Desde então, isso já vai para quase trinta anos que a gente vem se dedicando ao estudo das migrações.

\section{A migração internacional é um fenômeno dos nossos tempos? Como você $a$ vê enquanto pesquisadora hoje? \\ M. O.: Na verdade, a migração internacional no Brasil é tema recorrente desde o início do século passado. Atualmente nós temos uma intensificação dessa migração de outros países para o Brasil. Houve um momento que nós tivemos uma migração mais intensa de brasileiros para outros países, mas a migração internacional é recorrente no Brasil desde o início do século passado.}

\footnotetext{
* Márcia Oliveira (M.O.) é professora e pesquisadora da UFRR.

**Mestre em Sociologia na UNICAMP. Realizou esta entrevista em 4 de novembro de $2014 \mathrm{em}$ Manaus, Amazonas.
} 


\section{Por falar nisso, haveria uma teoria "geral da imigração"?}

M. O.: Existem muitas teorias sobre as migrações. Eu gostaria de destacar assim grandes clássicos que, desde o século passado, discutem a questão das migrações como George Simmel. Mais tarde a gente tem os trabalhos clássicos do Abdelmalek Sayad que faz uma discussão muito boa, que consegue trabalhar muito bem esta questão das migrações. Mas, na verdade o tema das migrações enquanto teoria vem provocando a sociologia desde o início da formação da sociologia enquanto ciência. Foi preocupação de Marx, de Durkheim, Frederick Engels, do próprio Weber, então a teoria geral da migração acompanha também a teoria geral da sociologia.

\section{Os desafios de hoje seriam os mesmos que os de há $\mathbf{5 0}$ anos?}

M.O.: Não. Acredito que a cada tempo nós temos novos desafios. Para novos tempos novos desafios. Mas os fatores que provocam a migração, os atenuantes, a própria condição da mobilidade humana, não é um fenômeno de agora. É um fenômeno já muito antigo na história de humanidade. Mas, o estudo disso é que vai então ganhando mais essas interfaces da atualidade. Se a cada tempo temos novos desafios, exigem-se novas teorias, novas abordagens para compreender e analisar os desafios das migrações. Na atualidade a gente fala que, por exemplo, para entender as migrações é preciso entender as especificidades. Por que é que a mulher migra, por que é que o migrante do interior vem para a cidade? Então a gente tem que entender todas essas nuances que alguns clássicos das teorias migratórias afirmam ser apenas por conta do fenômeno econômico. Atualmente a gente não concentra a experiência apenas no fator econômico, porque são inúmeras as situações que provocam as migrações, que definem as migrações. Então para além do trabalho, da mobilização para o trabalho, é preciso também pensar em outras formas de mobilização.

Na sua visão, que importância tiveram e têm os estudos sobre migrações e sobre imigrantes? Hoje podemos dizer que é sim importante estudar este tema?

M.O.: Claro, hoje para você entender a sociedade moderna, é preciso entender também seus migrantes. Ou seja, nós estamos diante de sociedades que estão praticamente centradas nas cidades, nos centros urbanos, e a grande característica desses centros é a questão migratória. Então, hoje é impossível você pensar a sociedade sem pensar junto com ela a sua dinâmica migratória. A recíproca também se aplica. A dinâmica migratória nos ajuda a entender as novas sociedades, ou seja, nos ajuda a atualizar nosso pensamento sobre a sociedade a partir da nossa compreensão do fenômeno migratório, da mobilidade humana.

Esse fenômeno migratório teria algum significado político? Ou melhor, o estudo da migração teria algum componente político?

M.O.: Eminentemente político. Pensar o fenômeno migratório hoje é pensar como estão organizados os Estados nacionais. Na relação com as migrações, no entendimento das migrações, como é que os Estados nacionais se apropriam 
das migrações enquanto fenômeno social? Os Estados nacionais também estão implicados nos fenômenos que provocam as migrações. Então falar de migrações na atualidade é um ato político, é um fenômeno, é também um implicativo político. Em se tratando das migrações, não dá para sermos neutros. Nós temos também que nos posicionar. Não é ser contra ou a favor das migrações. É o entendimento daquilo que significam as migrações para as sociedades modernas. Então, por isso que a questão política, o entendimento político da questão migratória é uma realidade, um fator importante para entendermos como é que os Estados nacionais se posicionam frente ao fenômeno. Como é que, por exemplo, na atualidade ainda se fala, no Brasil, do famoso imigrante ideal, que foi um imigrante pensado na época do Getúlio Vargas, com vários objetivos políticos? Um deles seria a história do branqueamento da raça. Por trás disso existe o elemento cultural, mas é uma atitude altamente política. Inclusive os acordos migratórios entre o Brasil, o Japão, a Itália, a Alemanha foram todos políticos. Então, não dá hoje para lidarmos com a questão migratória sem pensarmos em toda a questão política que envolve o debate. A própria forma dos Estados lidarem com o fenômeno representa uma conjuntura política. É importante entender ainda como é que os Estados também se apropriam das migrações a partir dos interesses econômicos.

\section{É ou não o Brasil, atualmente, um país de imigração?}

M.O.: O Brasil é um país de imigração. Não dá para compreendermos o Brasil sem compreendermos a gama de migrações que formam esse Brasil. $\mathrm{E}$ aqui, é lógico, existem grupos mais presentes, mais pertinentes nessa formação sociopolítica e econômica do Brasil. Mas é importante pensarmos o Brasil como um país de migrantes, e em alguma medida também o Brasil como produtor de migrantes para outros países. Então, tanto o Brasil é um país de recepção de migrantes, como também um país de trânsito de migrantes brasileiros para outros países e de migrantes de outros países que passam pelo Brasil e vão seguindo rumo a outros países.

O que estaria por trás da busca do Brasil pelos haitianos, sobretudo a partir de 2011? Fala-se de 2010, mas em 2010, por exemplo, só houve, de acordo com os dados do CNIg, quatro autorizações de trabalho, então os números mais expressivos da presença efetiva de haitianos no Brasil, pelos dados do CNIg, começam no ano de 2011. E como explicar que Amazonas seja um dos Estados por onde a maioria dos migrantes haitianos entram no Brasil?

M.O.: Aqui eu acho que nós teríamos que considerar, Kassoum, vários fatores. Dentre eles, eu poderia destacar o fechamento de alguns países que historicamente mantiveram relações de migrações com o Haiti, ou talvez até o saturamento, como é o caso da República Dominicana, Equador, Estados Unidos, França, que começaram a se fechar, ou por causa do saturamento ou por questões políticas mesmo, de políticas migratórias. E o fato de outros países fecharem as portas, logo iniciam-se as buscas por outros destinos. E outro fator interessante, que eu acho importante considerar é também o papel do Brasil no 
cenário econômico mundial. O Brasil aparece como um país em crescimento, o Brasil aparece como um país flexível nas suas relações de fronteira, nas relações migratórias, apesar de nós não termos uma política respeitável, com relação às migrações, mas nós aparecemos para o resto do mundo como um país flexível nas questões migratórias. Então, isso também pode ser um fator que propicia a migração. Os haitianos conheceram o Brasil, eu acredito, tem muito a ver com as relações de segurança internacional que o Brasil passou a exercer no Haiti, não a partir do terremoto, mas a partir da crise política. Também houve várias organizações não governamentais que estabeleceram parcerias entre Haiti e Brasil numa reciprocidade. Eu sei de várias rádios comunitárias no Brasil que foram aprender do Haiti a lidar com a comunicação alternativa. Eu sei de várias Organizações não governamentais que vão ao Haiti para aprender como lidar com crianças em situação de risco, e assim por diante. Então essas parcerias do movimento social, das ONGs e mesmo da iniciativa política, me parece que todos esses fatores contribuem para que o Haiti conheça o Brasil e vice-versa. Aqui também acho que o elemento religião dever ser levado em consideração. Parece-me que é um fator importante para nós entendermos a relação entre - Brasil e o Haiti. O fato de vários pastores religiosos, principalmente das igrejas pentecostais e das igrejas evangélicas do Brasil estarem no Haiti, acaba estabelecendo vínculos.

E também tem esse fator da Amazônia ser a entrada da porta dos fundos, funcionando como passagem para outras regiões do Brasil. Porta de entrada porque nós estamos na fronteira. O Haiti está para o norte do Brasil. A ideia de entrar no Brasil é pela fronteira. E a Amazônia aparece como uma porta de entrada que facilita e encurta as distâncias. Então o fato de estar na fronteira é interessante porque, eu falei com vários haitianos que dizem "a gente tinha na cabeça o Brasil de São Paulo e aí, de repente a gente está na Amazônia, muito longe de São Paulo". Então quer dizer, esse imaginário do Brasil como Rio de Janeiro, São Paulo, a impressão que se tem é essa dificuldade de entender um país do tamanho do Brasil, com um tamanho continental. Então se entende que chegar na Amazônia é o mesmo que chegar no Brasil, mas não exatamente naquele Brasil que se imaginava, que é São Paulo e Rio. Então, Amazônia me parece funcionar estrategicamente como fronteira, como porta dos fundos, a entrada pela porta dos fundos.

\footnotetext{
Algo que lembra a imigração haitiana no Brasil já teria acontecido na história da imigração brasileira?

M.O.: Com esse dado da documentação e de uma postura do Estado nacional brasileiro de estabelecer a questão da documentação imediata, me parece que não. É um fenômeno bem novo para o Brasil, que atualmente está inscrito como um país de destino de refugiados, mas nós ainda temos pouquíssimos refugiados à proporção daquilo que seria uma política de refúgio. Nós temos uma intensa presença de migrantes latino-americanos no Brasil. Para você ter uma ideia, só no Estado do Amazonas, nós temos mais de quarenta mil peruanos. Mas o fato migratório, nesse caso, com maior quantitativo dos países
} 
vizinhos não repercute tanto como no caso do Haiti porque a gente tem lidado com este fato migratório como uma questão histórica onde eles vão entrando aos poucos e, sem essa preocupação com a burocracia, da documentação pelo fato de nós estarmos lidando com fronteiras. Então, por exemplo, o peruano entra e sai diversas vezes no ano sem necessariamente passar por um controle de fronteira, um controle de documentação. Mas o diferencial é que nós temos muitos migrantes colombianos, peruanos, venezuelanos e guianenses vivendo na Amazônia sem documentos ${ }^{1}$. Essa preocupação que os migrantes haitianos tiveram de buscar a documentação é muito importante. Talvez isso se deva à larga experiência migratória que os haitianos têm noutros países. 0 conhecimento sobre a questão migratória documentada que os próprios migrantes já têm, o que, talvez, seja um fator que escapa ao controle dos peruanos, bolivianos, chilenos e colombianos que estão no Brasil há também muitos anos, mas que retardam a questão da regularização da documentação diferente do que vem ocorrendo com os haitianos, que colocam a questão da documentação como uma exigência da condição migratória. A gente tem peruanos aqui que, de vez em quando a gente tem que fazer anistias, campanhas para eles poderem se documentar, porque a documentação não é a preocupação primeira deles.

\section{A literatura sobre migrações associa a migração quase sempre com o} trabalho. As mulheres são parte expressiva do conjunto, hoje considerando algumas regiões como a chamada América Andina onde se constata, inclusive um maior número de mulheres migrando em termos de migrações internacionais em relação aos homens, quer dizer que as mulheres são parte expressiva hoje do conjunto dos migrantes internacionais. Quais os desafios para sua integração no mercado de trabalho brasileiro hoje?

M.O.: As mulheres têm um pouco mais de dificuldade de inserção no mercado de trabalho. No caso da migração haitiana há um fator que vem provocando a migração, que é a busca pelo trabalho. Isso me parece muito pertinente. Existem outros fatores que fazem o haitianos migrar, mas a busca pelo trabalho aparece como o principal. Existe um mercado para o trabalho do migrante já, quase que garantido aos homens. Os haitianos encontram este mercado aberto na construção civil, na área da produção de alimentos, na área da manutenção e serviços gerais. É um mercado de trabalho que não exige alta qualificação, é um mercado de trabalho que não está sendo completamente atingido pelos trabalhadores brasileiros, pelos trabalhadores locais. Daí, essa possível abertura ao mercado de trabalho do migrante, à mão de obra do migrante. Entretanto, é preciso considerar que existem outros fatores que fazem o haitiano migrar. Parece-me que o trabalho aparece como a principal motivação, mas outras coisas também motivam. Nesse caso, a mulher, encontra maior dificuldade porque esse mercado de trabalho não está garantido para ela, e aquilo que seria mercado de trabalho, que atualmente se abre à possibilidade do trabalho da mulher, que é o trabalho de meio tempo, o trabalho doméstico, não é um espaço de trabalho que a mulher haitiana almejava, esperava no Brasil. Aqui nós temos uma tensão muito grande, uma dificuldade muito grande, o que vai, assim, em linhas gerais, 
retardar um pouco mais o ingresso da mulher haitiana no mercado de trabalho no Brasil, ou talvez, provocar uma maior circulação nos postos de trabalho com relação aos homens. Não é que os haitianos encontram esse mercado dado, pronto. Eles vêm lutando também para conquistar esse mercado de trabalho, mas me parece que em tese seria um mercado de trabalho que já estaria mais facilitado para os homens do que para as mulheres. Entretanto, elas vêm criando mecanismos, criando alternativas e se inserindo onde é possível para garantir a manutenção de sua condição migratória a partir do mercado que não está dado, que ela tem que conquistar, que ela tem que fazer.

Como você avalia então, nesse caso, a política migratória brasileira diante do direito de circular reivindicado por alguns autores, o Brasil estaria tendo a oportunidade de propor um novo paradigma na política migratória para $o$ mundo?

M.O.: A nossa política migratória tem muitas lacunas. Primeiro, a gente sempre questiona afinal se nós temos de fato uma política migratória, porque nós estamos lidando com os migrantes ainda com uma lei bastante defasada, uma lei ainda da década de $1980^{2}$, baseada na lei de controle de fronteira, na lei de Segurança Nacional, que restringe muito o próprio conceito de migrante. Quer dizer, nós temos um Estatuto do Estrangeiro. Nós não temos uma política para o migrante. Entretanto, existe toda uma discussão, toda uma contribuição de vários teóricos, estudiosos no Brasil para pensarmos realmente uma política migratória. Neste sentido, aí sim acho que poderia estar pensando essa questão da migração como um direito, um direito de ir e vir, o direito de circulação para o trabalho, para outras questões também, o Brasil poderia sim aparecer como um produtor de novos paradigmas, um modelo de novos paradigmas para políticas migratórias. Entretanto, eu costumo sempre dizer que o Brasil assegura-nos o direito a migração, mas não nos assegura o direito de não migrar. Muitas vezes, nós não paramos para pensar que muitos migrantes são empurrados para a migração. Eu acho que era importante pensar também os elementos que provocam a migração compulsória. Ou seja, aquela migração forçada, sem um planejamento, sem um projeto migratório, sem condições de você se colocar realmente na circulação para o trabalho, para melhorar de vida com direitos e garantias. Então está garantido o direito de migrar e não está garantido o direito de não migrar.

\section{Notas}

"Como você viu o peruano dizendo que está há trinta anos no Brasil e não tem documentos", acrescentou a Márcia.

\footnotetext{
${ }^{2}$ Ela se refere ao Estatuto do estrangeiro que é de 1980 quando ainda havia ditadura no Brasil (1964-1985).
} 